\title{
Avaliação Crítica do Ecodesign Aplicado no Projeto de Embalagem de Lasanha Congelada para Consumidores Singles
}

\author{
Critical Assessment Of Ecodesign Applied In The Project Of Packaging Frozen \\ Lasagna To Singles Consumers
}

\author{
WITTMANN, Luiz Rogério; Mestre; Instituto Mauá de Tecnologia \\ rogeriowittmann@gmail.com.br \\ CABRAL, Antônio; Doutor; Instituto Mauá de Tecnologia \\ acabral@maua.br
}

\section{Resumo}

Há uma crescente conscientização do setor produtivo e sobretudo do segmento de embalagem da necessidade de desenvolver produtos e embalagens com menos impacto ambiental. Para atingir este objetivo as empresas precisam adequar suas atividades e produtos a esta realidade. Neste cenário, uma contribuição pode ser dada pelo Ecodesign que é uma área de conhecimento que agrupa um conjunto de ferramentas para otimizar o desempenho ambiental dos produtos e desta forma diminuir seu impacto no meio ambiente. Este trabalho identificou na literatura qual a metodologia de projeto mais utilizada no campo do Ecodesign e aplicou em um estudo de caso com os seguintes objetivos: a) avaliar a viabilidade da sua aplicação no sistema de embalagem de lasanha congelada destinada ao público single; b) comparar o desempenho ambiental das embalagens de lasanha de $350 \mathrm{~g}$ e $650 \mathrm{~g}$; c) propor uma embalagem alternativa para o produto. Para atingir estes objetivos foi elaborado um estudo de caso do Sistema de Embalagem de Lasanha à Bolonhesa Congelada. Os objetivos propostos foram atingidos por três motivos. Primeiro, foram analisados os impactos ambientais por ele causados; identificadas oportunidades, apresentadas propostas e estratégias para minimizá-los. Segundo, ao comparar o desempenho ambiental das embalagens de lasanha congelada de $350 \mathrm{~g}$ e 650 $\mathrm{g}$, o trabalho mostrou que o impacto ambiental das primeiras é menor porque, se o público single adquire a embalagem maior fatalmente haverá desperdício de alimento, o que não é aceitável. Por último, foi proposta uma embalagem alternativa com menor impacto ambiental, sem prejuízo da qualidade do produto.

Palavras Chave: Ecodesign; Embalagem; Lasanha congelada e Consumidores singles.

\begin{abstract}
There is a growing awareness of the productive sector and especially of the packaging segment of the need to develop products and packaging with less environmental impact. To achieve this goal companies need to tailor their activities and products to this reality. In this scenario, a contribution can be made by Ecodesign, which is an area of knowledge that brings together a set of tools to optimize the environmental performance of products and thus reduce their impact on the environment. This work identified in the literature the most used design methodology in the field of Ecodesign and applied in a case study with the following objectives: a) to evaluate the feasibility of its application in the frozen lasagne packaging system for the single public; b) compare the environmental performance of the lasagne packs of $350 \mathrm{~g}$ and $650 \mathrm{~g}$; c) propose an alternative
\end{abstract}


packaging for the product. In order to reach these objectives, a case study of the Frozen Bolognese Lasagna Packaging System was elaborated. The proposed objectives were achieved for three reasons. First, the environmental impacts caused by it were analyzed; identified opportunities, presented proposals and strategies to minimize them. Second, in comparing the environmental performance of frozen lasagne packs of $350 \mathrm{~g}$ and $650 \mathrm{~g}$, the work showed that the environmental impact of the first lasers is smaller because if the single public acquires the largest packaging fatally there will be food waste, which is not acceptable. Finally, an alternative packaging with less environmental impact was proposed, without prejudice to the quality of the product.

Keywords: Ecodesign; Packaging; Frozen lasagna and single consumers.

\section{Introdução}

Desde o início da década de 1990, com a criação do WBCSD - World Business Council for Sustainable Developer, nota-se que vários setores da indústria, incluindo fabricantes e usuários de embalagem, estão empenhados em diminuir o impacto ambiental de suas atividades. Este ano de 2018 a ONU (Organização das Nações Unidas) lançou uma campanha para conscientizar o mundo sobre os impactos dos resíduos gerados pelos materiais plásticos nos oceanos. Considerando que a maior parte dos resíduos plásticos são gerados por embalagens esta campanha levanta um alerta para o setor.

Quando se fala de embalagem é preciso entender que não se trata simplesmente de um invólucro para acondicionar ou adicionar valor a um produto, mas de um sistema definido como "um conjunto de operações, materiais e acessórios que são utilizados na indústria com a finalidade de conter, proteger e conservar os diversos produtos e transportá-lo aos pontos-de-venda ou utilização, atendendo as necessidades dos consumidores e/ou clientes a um custo adequado, respeitando a ética e o meio ambiente" (CABRAL, 1994). Trata-se, portanto, de "um sistema formado pela integração de agentes como fornecedores de matéria-prima, indústrias de bens de consumo, produtores de embalagem, varejistas, atacadistas, distribuidores, consumidores e meio ambiente" (CABRAL, 2003).

As relações da embalagem com os estudiosos do meio ambiente nem sempre foram muito amigáveis. Há quem defenda até a extinção das mesmas e a venda de produtos sem embalagem, uma vez que ecologistas a apontam como responsável pelos resíduos urbanos, questionam sua importância e pressionam os governos a adotarem políticas mais rígidas para o setor. No Brasil, em 2010 foi aprovada a Política Nacional de Resíduos Sólidos, sua principal característica está na responsabilidade compartilhada pelo ciclo de vida dos produtos, com ênfase na logística reversa, coleta seletiva e gestão dos resíduos sólidos. Contudo, essa responsabilidade que é atribuída à embalagem não é justa porque, na verdade, ela é um meio de conservação de alimentos, aumentando sua vida de prateleira e um veículo que os leva aos consumidores garantindo a segurança alimentar.

O crescimento econômico gera maior consumo de vários tipos de produtos e suas embalagens, algumas com estruturas complexas, se descartadas de maneira irresponsável, podem gerar impactos ambientais desproporcionais ao benefício de proteção do conteúdo. Dentro do universo das embalagens, um dos segmentos que mais chama a atenção é o setor de alimentos e dentro dele a de produtos de porção única. O motivo é aparentemente simples: estes produtos são fabricados na medida certa, ou na quantidade correta para evitar o desperdício. No entanto, porque utilizam mais embalagem por quilograma de alimento, há o risco de aumentarem o impacto 
ambiental se descartados de forma inadequada. Surge neste contexto, o que se convencionou chamar de "dilema da embalagem", resumido numa questão - Que alternativa é melhor: embalagens menores, com quantidades adequadas para o consumidor, com risco de aumentar o impacto ambiental, ou embalagens maiores, com maior peso líquido, com o risco de aumentar o desperdício de alimentos? Esta questão enuncia um problema não estruturado complexo, uma vez que há muitos agentes envolvidos em todo ciclo de vida do produto e o próprio impacto ambiental é difícil de ser mensurado.

$\mathrm{Na}$ área ambiental existem duas categorias de ações para minimizar este dilema que podem ser divididas em pós-consumo e pré-consumo. Na primeira não existem mudanças no projeto original das embalagens e procura-se minimizar o seu impacto ambiental depois de descartada pelo usuário. Muito embora a reciclagem seja a solução mais difundida, seus resultados dependem diretamente da eficiência da coleta seletiva e de políticas de incentivo para revalorização dos materiais. Por sua vez, as ações pré-consumo, concentram-se na fase de projeto e objetivam criar embalagens e produtos sustentáveis, ou seja, com menos impacto ambiental e social em todas as fases do ciclo de vida.

A crescente demanda por produtos sustentáveis fez emergir no campo do design de produtos uma área de conhecimento chamada de Ecodesign. Dentre os autores de destaque nesta área podem ser citados os seguintes. Fiksel (1995) nos EUA, que define o Design for Environmental, como "um conjunto de procedimentos de projeto com objetivo de criar produtos e processos ecoeficientes", ele tem uma abordagem voltada a processos e tecnologias de produção mais limpa. Brezet e Hemel (1997) apresentam um manual para as empresas desenvolverem produtos sustentáveis, foi escrito em colaboração com a Organização das Nações Unidas (ONU) e a Delft University na Holanda. Manzini e Vezzoli (2008) na Itália, dois autores amplamente citados nos estudos de design sustentável, propõem uma mudança no pensamento projetual dos designers com objetivo de desenvolver produtos e serviços sustentáveis. Resumindo, Fiksel foca nos processos, Manzini e Vezzoli no pensamento projetual e Brezet e Hemel na metodologia. Todos estes autores apresentam inúmeros exemplos de aplicações do Ecodesign, porém nenhum deles tem o foco no setor de embalagens. Há, portanto, muito que se fazer nesta área.

Dentro do universo das embalagens para alimentos observa-se a demanda crescente por pratos prontos congelados. Segundo a pesquisa Fiesp/Ibope Brasil Food Trends 2020 (MADI, 2010), $34 \%$ dos consumidores brasileiros de alimentos nas classes sociais $A B$ e $C$, buscam a praticidade dos alimentos industrializados congelados. Outro dado importante é o crescimento da população single, pessoas que vivem sozinhas. Elas representavam 9,2\% do total da população do Brasil em 2000, passando para $12,1 \%$ em 2010, segundo o último Censo Demográfico. Estas duas tendências são convergentes, porque os pratos prontos congelados são alvo preferencial do público single que procura produtos práticos.

Os fatos relacionados até este ponto: a preocupação dos estudiosos com a redução do impacto ambiental causado por produtos e embalagens; as ações ambientais focadas no pósconsumo; a pouca disponibilidade de estudos de Ecodesign para embalagens; o "dilema da embalagem"; o crescente mercado de produtos para consumidores single, caracterizado pela alta relação peso de embalagem/peso de alimento; e a importância da lasanha congelada nesse segmento do mercado; desenham o cenário que justifica a execução deste trabalho, cujos objetivos foram: 
- Avaliar as metodologias e ferramentas disponíveis no campo do Ecodesign;

- Analisar os impactos ambientais do sistema de embalagem da lasanha congelada e identificar oportunidades de minimizá-los;

- Comparar o desempenho ambiental das embalagens de lasanha de $350 \mathrm{~g}$ e $650 \mathrm{~g}$;

- Propor uma embalagem alternativa para o produto.

Para atingir estes objetivos foi feito um estudo de caso aplicado ao sistema de embalagem do produto congelado Lasanha à Bolonhesa fabricado por uma das indústrias brasileiras. A expectativa dos autores é que este trabalho possa contribuir na divulgação do Ecodesign aos profissionais interessados em projetar sistemas de embalagem com responsabilidade ambiental.

\section{Ecodesign}

Desde a década de 1990 há uma preocupação da sociedade incluindo os setores produtivos em minimizar os impactos ambientais das suas atividades. Neste cenário, emergiram iniciativas para reduzir os impactos ambientais dos produtos. Em 1992, nos EUA, as indústrias do setor eletroeletrônico sob a liderança da American Eletronics Association, passaram a ponderar sobre o impacto ambiental de seus produtos (FIKSEL, 1995). Isto resultou no desenvolvimento de procedimentos para criar produtos ecologicamente mais adequados. Estas práticas ficaram conhecidas sob o nome de Design for Environment (DfE). Fiksel (1995) as define como "um conjunto específico de procedimentos de projeto com objetivo de criar produtos e processos ecoeficientes" ou "um sistema de projetar onde o desempenho respeita o meio ambiente, a saúde e a segurança em todo o ciclo de vida do produto e do processo". Dentro desta óptica o $D f E$, é uma metodologia de projeto com objetivo de criar produtos com responsabilidade ambiental a ser aplicada no departamento de desenvolvimento de produtos das empresas. Alguns possíveis benefícios que motivam as empresas a adotá-la, relacionados pelo National Research Council do Canadá, são os seguintes:

- Desenvolver o senso de responsabilidade ambiental, mediante aumento da consciência ambiental no nível das gerências das empresas e por consequência dos demais funcionários (ótica sistêmica);

- Reduzir custos com a diminuição de gastos com materiais, energia e descarte dos produtos;

- Melhorar a imagem das empresas, que passam a ser consideradas ambientalmente responsáveis;

- Incremento no nível de qualidade do produto como consequências do melhor desempenho ambiental;

- Adequar-se à legislação ou preparar-se para tal;

- Adequar-se às normas internacionais, como, por exemplo, aos ditames do relatório técnico ISO / TR 14062 (ABNT, 2004) que pode tornar-se uma norma internacional e ser exigida das empresas para exportarem seus produtos, evitando barreiras nãocomerciais;

- Atender a demanda dos consumidores que somente adquirem produtos que causam mínimo impacto ao meio ambiente.

Supondo que uma empresa decida utilizar o Ecodesign, as principais referências bibliográficas, em ordem cronológica são: FIKSEL (1995) o primeiro a tratar do tema no seu livro "Design for environment: creating eco-efficient products and processes"; BREZET e HEMEL (1997) 
que escreveram o manual intitulado "Ecodesign: a promising approach to sustainable production and consuption"; LEWIS, GERTSAKIS et al (2001) que escreveram o livro "Design + Environment: a global guide to designing greener goods"; o relatório técnico ISO / TR 14062 (ABNT, 2004) sobre a integração dos aspectos ambientais nos produtos; Manzini e Vezzoli (2008), dois autores citados na área do design sustentável, propõem uma mudança no pensamento projetual a partir do ponto-devista dos designers de produto, importante ressaltar este ponto, porque muito da literatura sobre Ecodesign advém da área de engenharia que está preocupada sobretudo em otimizar processos e materiais, deixando de lado o pensamento centrado nas necessidades do usuário que é inerente ao campo do design.

Neste trabalho os termos $D f E$ e Ecodesign são tratados como sinônimos, ou seja, uma metodologia de projeto com vistas a minimizar os potenciais impactos ambientais de produtos. Entretanto, é de conhecimento dos autores que para o campo do design, este conceito assume uma dimensão mais ampla que na engenharia de produto, uma vez que não se restringe a melhorias pontuais no projeto, neste campo o Ecodesign é entendido como uma área de conhecimento e está relacionado as mudanças no pensamento projetual que não se restringe a melhorias pontuais específicas, mas se preocupa com a inserção daquele produto na comunidade do ponto-de-vista financeiro, ambiental e social.

A contribuição mais significativa para estabelecer uma metodologia para o design de produtos sustentáveis foi o manual publicado por BREZET e HEMEL (1997). Nele, os autores estabeleceram o passo-a-passo para as empresas aplicá-lo em seus projetos, servindo de base para outros manuais como o canadense "Design for environment guide" (NATIONAL RESEARCH COUNCIL, 2004) e o centro-americano "Ecodiseño en CentroAmerica" (TUDELFT, 2005).

\subsection{Metodologia do Ecodesign}

A metodologia apresentada por BREZET e HEMEL é composta de seis etapas que estão resumidas nos itens a seguir.

\subsubsection{Organizar a equipe de projeto}

Consiste em selecionar um grupo interdisciplinar composto de um coordenador que conheça o Ecodesign, e de representantes das áreas de desenvolvimento de produto, meio ambiente, marketing, vendas, logística e produção. A natureza sistêmica do projeto ecoeficiente requer a participação e integração dos diversos setores da empresa.

\subsubsection{Seleção do produto ou embalagem}

Com base numa relação de produtos, e alinhada com a estratégia da empresa, a equipe formada seleciona aquele que será o objeto do estudo. Para tanto, utiliza uma matriz de seleção que se fundamenta em critérios que podem ser: otimização de custos de produção, qualidade do produto, inovação, potencial de vendas e de melhora ambiental. Estabelecidos os critérios, a equipe atribui notas em ordem crescente de importância para cada um dos produtos. Aquele que obtiver maior soma de pontos será o escolhido.

\subsubsection{Análise do perfil ambiental}

A análise do perfil ambiental consiste em levantar os aspectos ambientais do sistema do produto ou do sistema de embalagem em todo seu ciclo de vida para identificar os pontos críticos e como estes se relacionam com as etapas do processo entre si e com o meio ambiente. Para 
conduzir tal análise, é necessário definir, como condições de contorno, qual a função do sistema, estabelecer com clareza os seus limites e indicar uma unidade funcional para facilitar comparações.

De acordo com a metodologia, podem ser utilizadas duas ferramentas: a Análise de Ciclo de Vida (ACV) e a Matriz de Inventário também chamada de Metmatrix. Esta etapa, a mais crítica devido à dificuldade de coletar os dados, deve ser conduzida da forma mais criteriosa possível. A ACV, segundo a ISO / TR 14040 (ABNT, 2001), é uma técnica para avaliar os aspectos ambientais e impactos potenciais ao longo da vida de um produto, desde a fabricação dos insumos utilizados, até a disposição final. A Metmatrix é uma ferramenta que agrupa o consumo de materiais, de energia e emissões em cinco estágios do ciclo de vida: matéria-prima utilizada, produção, distribuição, consumo e descarte. A peculiaridade desta ferramenta é que todas as etapas referentes a um estágio do ciclo de vida são agrupadas e somadas na mesma célula. Por exemplo, no caso de uma embalagem de refrigerante de plástico, o consumo de materiais agrupa o plástico usado na garrafa, no rótulo, na tampa e a caixa de embarque na célula de matéria-prima.

A metodologia Metmatrix não tem o rigor metodológico da ACV, mas é um excelente guia para desenvolver ou ajustar projetos sob a ótica da responsabilidade ambiental. Antes de utilizá-la é necessário preparar o fluxograma do sistema do produto, e, dentro dos limites que se deve estabelecer, gerar uma lista de inventário de todos materiais, gastos de energia e emissões.

\subsubsection{Seleção das estratégias para o projeto}

Selecionadas as ações ambientais, definem-se as mais viáveis utilizando uma matriz de decisão que as analisa segundo critérios pré-definidos, como, por exemplo, viabilidade técnica, viabilidade financeira, qualidade e prazo (curto, médio ou longo). É fundamental que a matriz evidencie as melhorias esperadas. Assim, as estratégias que atenderem os critérios estabelecidos pela equipe são escolhidas para o projeto.

As estratégias podem, também, ser selecionadas com base no Círculo de Estratégias exemplificado na Figura 1. Nele as circunferências representam os níveis de eficiência ambiental que variam de 0 (ruim) a 5 (excelente), e os oito pontos são associados às fases do ciclo de vida. $A$ cor clara representa o perfil ambiental existente e a escura o perfil almejado. Cada etapa do ciclo de vida possui possíveis estratégias e suas ações correspondentes, e, portanto, cada lista deve ser complementada pela equipe encarregada de desenvolver o projeto. 


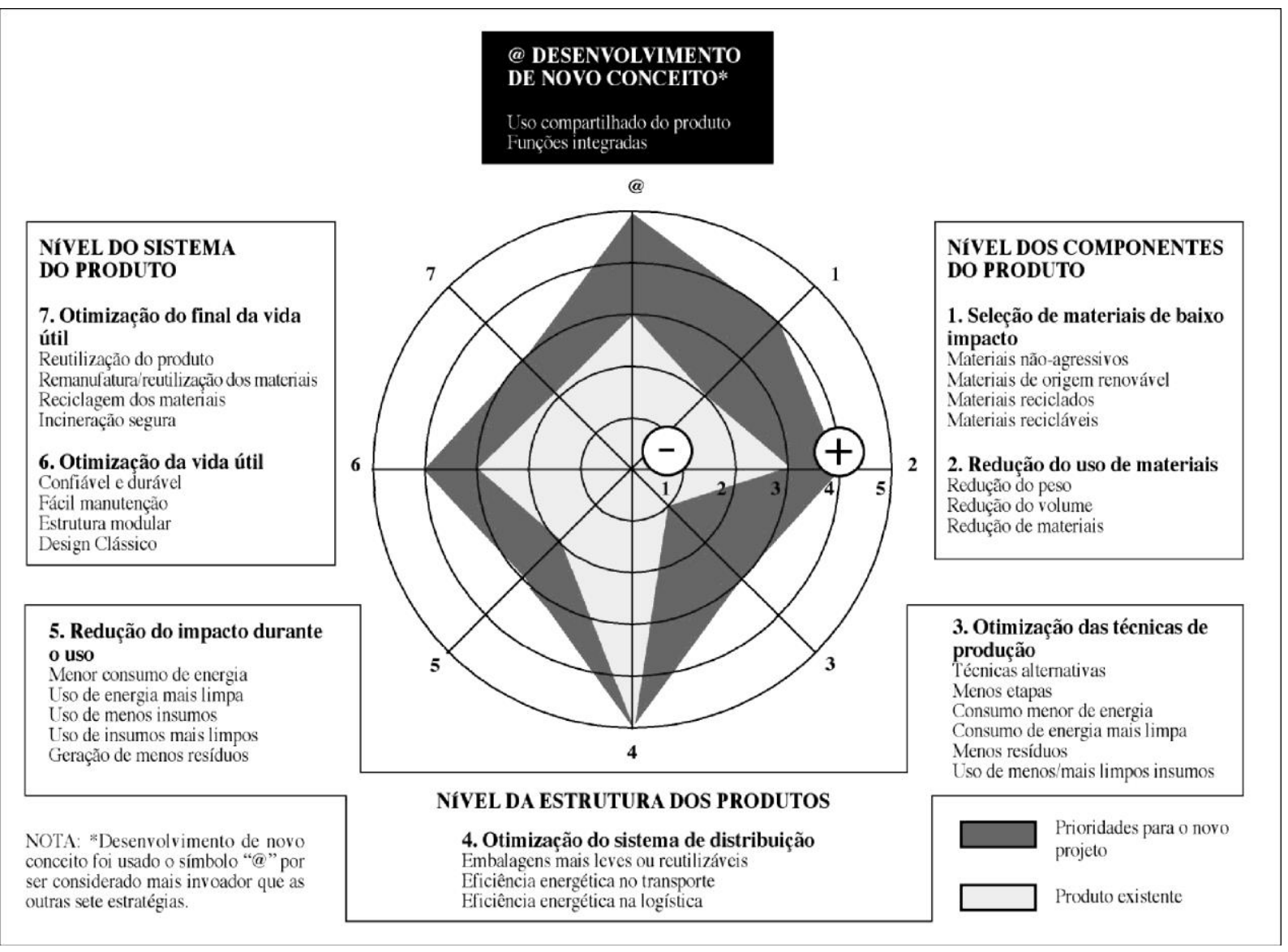

Fonte: Brezet e Hemel, 1997.

\subsubsection{Especificação técnica do novo produto}

Definidas as ações a adotar no projeto, a equipe deve concretizar estas alternativas e detalhá-las tecnicamente. No caso de embalagem, especificar materiais, selecionar fornecedores, determinar o custo sob o ponto de vista sistêmico, verificar aspectos legais e todos os demais itens necessários ao correto desenvolvimento do projeto.

\subsubsection{Avaliação do desempenho ambiental}

A última etapa da metodologia consiste em avaliar os resultados do projeto, ou seja, o desempenho ambiental do novo produto ou da nova embalagem, como descrito no item 2.1.3 Recomenda-se ainda a produção de protótipos para viabilizar os testes necessários.

\section{Método}

Para se aplicar a metodologia do Ecodesign foi conduzido um estudo de caso aplicado ao sistema de embalagem do produto congelado Lasanha à Bolonhesa fabricado por uma das indústrias brasileiras. $O$ estudo de caso (único) ou de casos (múltiplos) é um método que analisa a atividade de um ou mais sistemas ou organizações, departamentos ou setores (WESTBROOK, 1985 e YIN, 1989), investigando um fenômeno no cotidiano das empresas, estudando situações em que as fronteiras entre o fenômeno e o contexto não são claras e usa múltiplas formas de coleta de informação. Sua generalização é difícil porque necessita muitas visitas ou contatos com a empresa, ou com os profissionais envolvidos, é necessário extremo cuidado para evitar a influência do pesquisador na interpretação das informações colhidas. Todas as precauções foram tomadas para 
que os resultados fossem analisados e propostas apresentadas de forma a evitar qualquer viés dos autores. A seguir, estão as seis etapas do Ecodesign e sua aplicação neste estudo:

\subsection{Organizar a equipe de projeto}

A equipe do projeto para este trabalho, constituiu-se dos autores e dos profissionais do departamento de desenvolvimento de embalagem da empresa que forneceram as informações referente aos processos internos de produção e logística.

\subsection{Seleção do produto e embalagem}

O produto selecionado, lasanha congelada (Figura 2) pertence à categoria de pratos prontos congelados, que consiste em produtos previamente preparados, acondicionados nas embalagens e depois congelados para manter suas qualidades. Para serem consumidos basta descongelar e aquecer em forno micro-ondas ou convencional. A vida útil é determinada pelos ingredientes mais críticos que, geralmente, são as carnes. As lasanhas são compostas basicamente por três processos: preparo da massa, do molho e envase nas embalagens (SARANTÓPOULOS, 2001).

Figura 2 - Cartucho (A) e Bandeja (B) para lasanha congelada

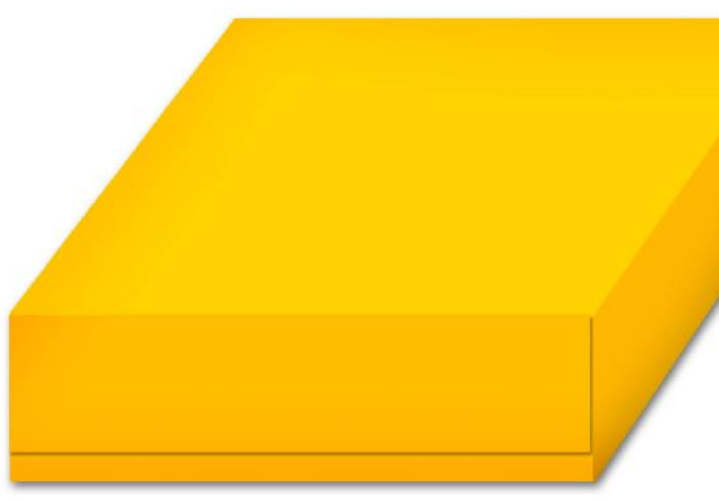

(a)

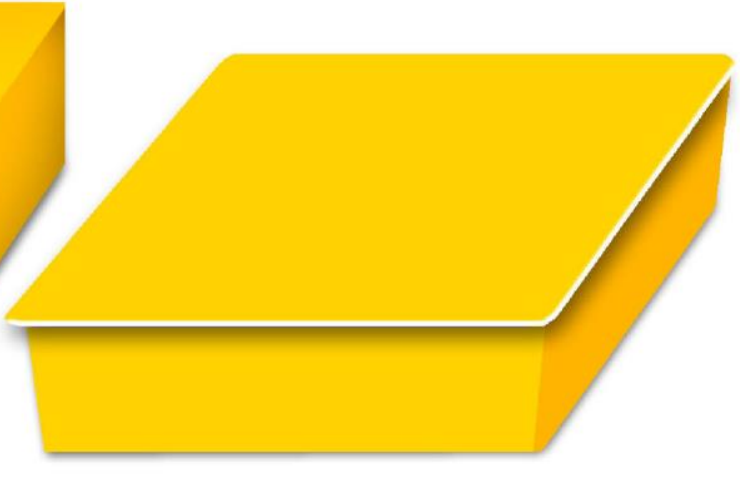

(b)

As especificações técnicas deste sistema, tanto dos materiais, processos de produção e distribuição são iguais tanto na versão de $350 \mathrm{~g}$ com na $650 \mathrm{~g}$, excetuando as dimensões das embalagens (Quadro 1). Vale esclarecer a definição para os tipos de embalagens considerados neste trabalho: primária, está em contato direto com o produto; display, acondiciona a bandeja e fica exposta no ponto-de-venda; secundária, caixa de embarque, agrupa uma unidade de vendas para o varejo das embalagens display. 
Quadro 1 - Características do sistema de embalagem lasanha congelada

\begin{tabular}{|l|l|l|l|}
\hline Características & Embalagem primária & Embalagem display & Embalagem Secundária \\
\hline Modelo & Bandeja de papel cartão & Cartucho & Cartucho normal \\
\hline Material & $\begin{array}{l}\text { Papel cartão revestido com } \\
\text { poliéster } 373 \mathrm{~g} / \mathrm{m}^{2}\end{array}$ & $\begin{array}{l}\text { Papel cartão } 278 \mathrm{~g} / \mathrm{m}^{2} \mathrm{da} \\
\text { marca Klakoad (Klabin) }\end{array}$ & $\begin{array}{l}\text { Papelão ondulado } 4,8 \mathrm{~g} / \mathrm{m}^{2} \\
\text { onda C }\end{array}$ \\
\hline Impressão & Off-set 6 cores + verniz UV & Off-set 6 cores + verniz UV & Flexografia 2 cores \\
\hline Funções & $\begin{array}{l}\text { Acondicionar, conservar e ser } \\
\text { própria para preparar a lasanha }\end{array}$ & $\begin{array}{l}\text { Acondicionar embalagem } \\
\text { primária, informações legais e } \\
\text { de marketing, exposição no } \\
\text { ponto de venda }\end{array}$ & $\begin{array}{l}\text { Acondicionar embalagens } \\
\text { display, otimizar } \\
\text { paletização e uniformizar } \\
\text { unidade de venda }\end{array}$ \\
\hline Requisitos & $\begin{array}{l}\text { Resistência a umidade, gordura, } \\
\text { baixas e altas temperaturas (- } \\
\left.12^{\circ} \mathrm{C} \text { a }+220^{\circ} \mathrm{C}\right) \text { em fornos } \\
\text { convencionais e micro-ondas }\end{array}$ & $\begin{array}{l}\text { Resistência a umidade, a luz, } \\
\text { a baixas temperaturas (-12 }{ }^{\circ} \mathrm{C} \text { ) } \\
\text { e mecânica }\end{array}$ & $\begin{array}{l}\text { Proteção mecânica, } \\
\text { identificação do produto }\end{array}$ \\
\hline
\end{tabular}

Fonte: Os autores.

\subsection{Análise do perfil ambiental}

O ponto mais crítico da metodologia está no levantamento de dados. Uma vez que as fontes são as mais diversas, assim como o corpus e as ferramentas para coletar os dados são específicas para cada tipo de dado. Deste modo, o autor recorreu a uma série de fontes e instrumentos de coleta para chegar aos valores apresentados, por se tratar de um estudo qualitativo, os dados foram comparados com outras pesquisas.

\subsubsection{Premissas e limites do sistema embalagem}

Para determinar uma unidade de valor para quantificar o impacto ambiental do sistema analisado foram estabelecidas as seguintes premissas:

- Função do sistema de embalagem: acondicionar lasanha, atendendo à definição apresentada no item 1 deste trabalho;

- Limites do sistema: esquematizado na Figura 3, engloba as etapas de produção da embalagem, linha de envase, logística, uso do produto e disposição final, o fluxograma de produção da Figura 5 detalhas as etapas consideradas;

- Unidade funcional: determinada em comum acordo com a empresa, é $1000 \mathrm{~kg}$ de produto o que corresponde a:

Lasanha $350 \mathrm{~g}=2857$ unidades ou $1000 \mathrm{~kg}$ de produto;

$>$ Lasanha $650 \mathrm{~g}=1538$ unidades ou $1000 \mathrm{~kg}$ de produto. 
Figura 3 - Limites do sistema de embalagem

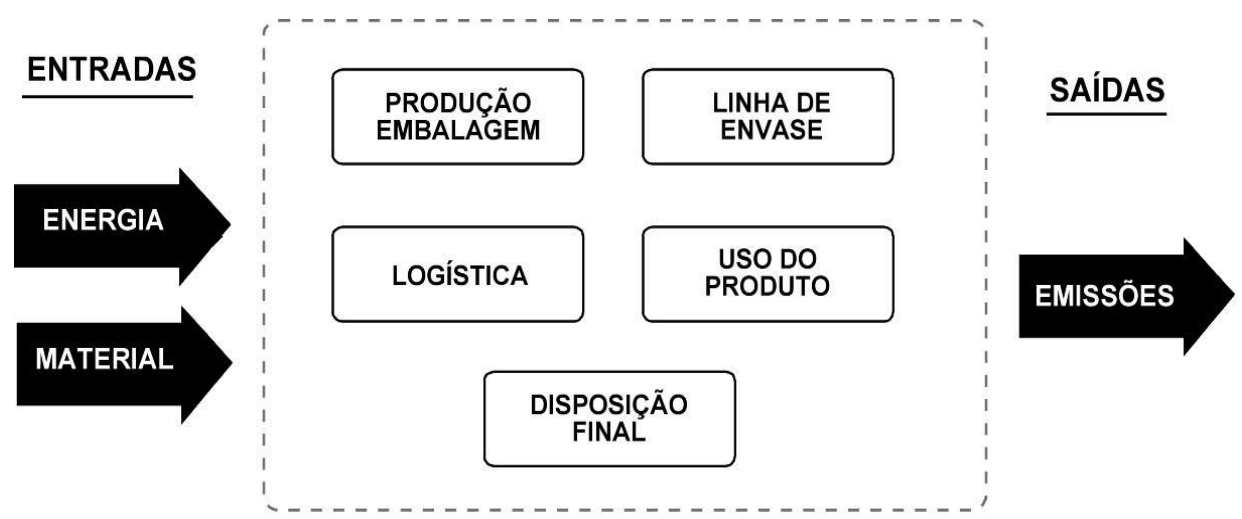

Limites do sistema

Fonte: Os autores.

Figura 5 - Fluxograma do sistema de lasanha congelada

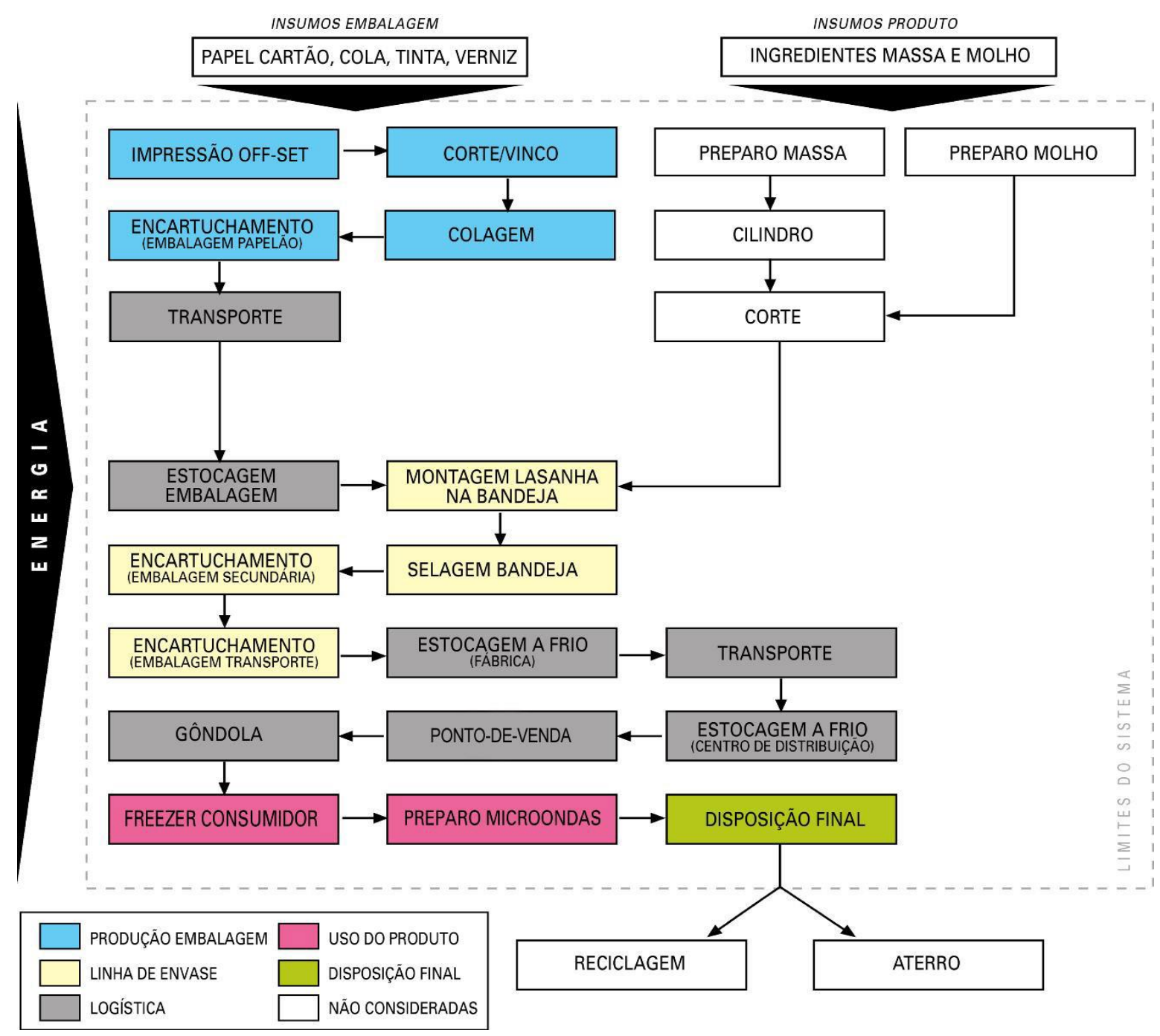

Fonte: Os autores. 


\subsubsection{Levantamento e tratamento dos dados}

Depois da coleta dos dados brutos eles foram tratados com o uso da matriz de inventário descrito na metodologia do Ecodesign. Outras referências bibliográficas foram consultadas para verificar a consistência destes dados (BRASIL, 2006; CERTEL, 2006; CETEA, 2006). A seguir são descritos como foram obtidos os dados utilizados na Tabela 1:

- Fabricação, estocagem e consumo do produto: fabricante de lasanha e de equipamentos de embalagem (BOSCH, 2000), a própria empresa forneceu os dados referentes ao consumo de energia da linha de produção, além disso o autor consultou o manual da máquina de envase com as informações técnicas, o consumo de energia na refrigeração do estoque também foram fornecidos, em relação ao gasto para descongelar a lasanha no micro-ondas e da lava-louças o autor consultou os manuais destes equipamentos para estimar os valores;

- Transporte: distâncias dos trajetos foram fornecidos pela fabricante da lasanha, com base em informações técnicas do motor e modelo do caminhão obtidos em manuais, foram estimados o consumo de combustível e as emissões de CO2 por quilômetro rodado;

- Materiais de embalagem: fornecedor de embalagens cartonadas e fabricante de equipamentos (BOBST, 2006), foram obtidos dados diretamente dos fabricantes do papel cartão e da gráfica que imprime os cartuchos, outras informações como consumo da tinta foram obtidas pela pesagem em equipamento de precisão de uma amostra impressa e outro sem impressão.

Estabelecidas as condições de contorno do trabalho, foi preparada a matriz de inventário (Quadro 2), que relaciona os itens considerados nos cálculos de consumo de materiais e de energia e as emissões em cada uma das cinco etapas do processo. 
Quadro 2 - Matriz de inventário (Metmatrix) do sistema de embalagem de lasanha congelada $350 \mathrm{~g}$ e $650 \mathrm{~g}$

\begin{tabular}{|c|c|c|c|}
\hline Etapas & Materiais (entradas / saídas) & Energia & Emissões (saídas) \\
\hline $\begin{array}{l}\text { Produção } \\
\text { embalagem }\end{array}$ & $\begin{array}{l}\text { Papel cartão } \\
\text { Papel cartão revestido com pet } \\
\text { Verniz UV } \\
\text { Tinta }\end{array}$ & $\begin{array}{l}\text { Impressora off-set } \\
\text { Corte / vinco } \\
\text { Dobradeira }\end{array}$ & $\begin{array}{l}\text { Aparas de papel cartão } \\
\text { Emissões off-set }\end{array}$ \\
\hline $\begin{array}{l}\text { Linha de } \\
\text { envase }\end{array}$ & $\begin{array}{l}\text { Ingredientes massa e molho } \\
\text { Cartucho papel cartão } \\
\text { Bandeja papel cartão revestido } \\
\text { com pet } \\
\text { Tampa de papel cartão } \\
\text { revestido com pet }\end{array}$ & Linha de envase & ----- \\
\hline Logística & $\begin{array}{l}\text { Caixas papelão } \\
\text { Diesel }\end{array}$ & $\begin{array}{l}\text { Trajeto: Gráfica - fábrica } \\
\text { Trajeto: fábrica - CD (frio) } \\
\text { Trajeto: CD - PDV (frio) } \\
\text { Câmara fria fábrica } \\
\text { Câmara fria Centro Distribuição } \\
\text { Gôndolas frias nos PDV's }\end{array}$ & $\begin{array}{l}\mathrm{CO}_{2} \\
\text { Amônia } \\
\text { Caixas papelão }\end{array}$ \\
\hline $\begin{array}{l}\text { Uso do } \\
\text { produto }\end{array}$ & Pratos / Talheres & $\begin{array}{l}\text { Estocagem freezer } \\
\text { Preparo microondas }\end{array}$ & \\
\hline $\begin{array}{l}\text { Disposição } \\
\text { final }\end{array}$ & -------- & $\begin{array}{l}\text { Trajeto embalagens: residência - } \\
\text { aterro ou residência - triagem }\end{array}$ & $\begin{array}{l}\text { Cartucho papel cartão } \\
\text { Bandeja / tampa de } \\
\text { papel cartão revestido } \\
\text { com pet }\end{array}$ \\
\hline
\end{tabular}

NOTAS: PDV - Pontos de Venda, CD - Centro de Distribuição

Fonte: Os autores.

A Tabela 1 mostra todos os resultados e propõe duas situações para o produto de maior tamanho: a ideal, na qual o consumidor single adquire uma embalagem de $650 \mathrm{~g}$ de lasanha congelada, consome parte do produto e o armazena em refrigerador para outra refeição, configurando duas refeições; a de descarte das sobras, na qual o consumidor single adquire uma embalagem de $650 \mathrm{~g}$ de lasanha congelada, consome $450 \mathrm{~g}$ do produto e descarta as $200 \mathrm{~g}$ restantes.

A análise cuidadosa da Tabela 1, aparentemente complexa, permite os seguintes comentários:

- O consumo total de materiais - fabricação e descarte de aparas - do sistema da lasanha $350 \mathrm{~g}$ é maior, por kg de lasanha, que o da $650 \mathrm{~g}$, confirmando que a embalagem single utiliza proporcionalmente mais material para acondicionar o produto;

- A embalagem $350 \mathrm{~g}$ consome mais energia - produção e consumo - por kg de lasanha do que aquela que contém $650 \mathrm{~g}$. É importante ressaltar que a primeira também consome mais energia nos fornos de micro-ondas utilizados para aquecer o produto;

- Quando há o descarte de lasanha, as emissões, embora menores em kg, são mais nobres porque trata-se de alimento sendo jogado no lixo. 


\section{Artigo Completo}

Tabela 1 - Inventário de materiais, energia e emissões por $1000 \mathrm{~kg}$ de lasanha $350 \mathrm{~g}$ e $650 \mathrm{~g}$ atuais

Etapas do processo

Produção embalagem

\section{Cartuchos}

Bandejas

Tampas

Impressão cartuchos: tinta + verniz UV

Impressão bandejas: tinta + verniz UV

Impressão tampas: tinta + verniz UV

Corte e vinco cartuchos

Corte e vinco bandejas

Corte e vinco tampas

Total produção embalagem

Total produção embalagem por kg produto $\left(^{\star}\right)$

Linha de envase

Cartuchos

Bandejas

Tampas

Linha de envase dedicada e contínua

Total linha de envase

Total linha de envase por $\mathrm{kg}$ produto $\left(^{*}\right)$

Logística

Embalagens papelão ondulado

Combustível - diesel

Transporte embalagens gráfica - fábrica

Transporte refrigerado fábrica - CD

Transporte refrigerado CD - PDVs

Estocagem câmara fria fábrica

Estocagem câmara fria $C D$

Gôndolas frias nos PDVs

Gás carbônico

Total logística

Total logística por $\mathrm{kg}$ de produto $\left({ }^{*}\right)$

Uso do produto

Água para lavar a louça

Estocagem congelador doméstico

Preparo do produto - microondas

Total uso do produto - situação ideal ${ }^{* \star}$

Total uso do produto por kg produto - situação ideal $\left(^{*}\right)$

Total uso do produto - descarte sobras

Total uso do produto por $\mathrm{kg}$ produto - descarte sobras (*)

Disposição final

Cartuchos

Bandejas

Tampas

Produto (situação ideal)

Produto (descarte sobras)

Total disposição final - situação ideal

Total disposição final por kg produto - situação ideal (*)

Total disposição final - situação com descarte sobras

Total disposição final por $\mathrm{kg}$ produto - situação com descarte s

TOTAL - SITUAÇÃO IDEAL

TOTAL POR kg PRODUTO - SITUAÇÃO IDEAL (*)

TOTAL - SITUAÇÃO COM DESCARTE DE SOBRAS

TOTAL POR kg PRODUTO - SITUAÇĀO COM DESCARTE DE SC

Materiais, $\mathbf{k g}$

Energia, kWh

Emissões, $\mathbf{k g}$

Lasanha $650 \mathrm{~g}$ Lasanha $350 \mathrm{~g}$ Lasanha $650 \mathrm{~g}$ Lasanha $350 \mathrm{~g}$ Lasanha $650 \mathrm{~g}$

$\begin{array}{cc}99 & 83 \\ 46 & 35 \\ 23 & 24 \\ 2 & \\ 1 & \\ <1 & <1 \\ --- & - \\ --- & - \\ -- & 145 \\ 171 & 0 \\ 0,2 & \\ & \\ 66 & 47 \\ 37 & 28 \\ 22 & 19 \\ --- & - \\ \mathbf{1 2 5} & 94 \\ \mathbf{0 , 1} & 0,1 \\ 52 & 4 \\ 8 & - \\ --- & - \\ --- & - \\ --- & - \\ --- & - \\ --- & - \\ --- & 54 \\ --- & \\ \mathbf{6 0} & - \\ \mathbf{0 , 1} & \end{array}$

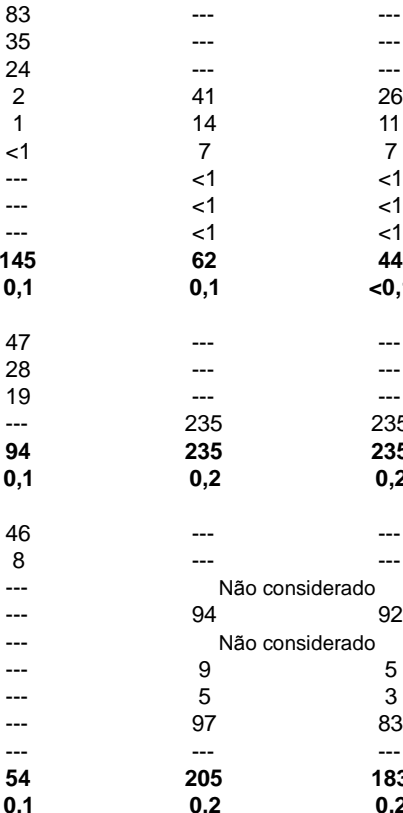

35

10
2

26

7

$<0,1$

0,1

47

38

8
5

Não considerado

74

628
702

702
0,7

702

$\begin{array}{lll}702 & 0,7 & 0,4\end{array}$

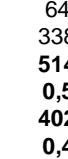

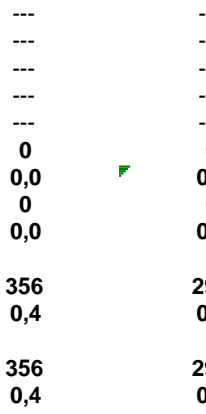

*) Desempenho Ambiental é definido como o consumo ou a emissão por $\mathrm{kg}$ de produto. ${ }^{* *}$ Valor considerando a energia gasta para armazenar e reaquecer a lasanha de novo Legenda

CD - Centro de Distribuição de produtos da empresa

PDV - Pontos de Venda

Situação ideal - todo o produto é consumido, sendo que as eventuais sobras da bandeja $650 \mathrm{~g}$ são armazenadas em refrigerador para uso posterior

Descarte sobras de produto: consumidas $450 \mathrm{~g}$ de lasanha e descartadas $200 \mathrm{~g}$ de cada uma das 1538 bandejas que compõem $1000 \mathrm{~kg}$ de produto.

Fonte: Os autores.

A Tabela 1 apresenta ainda o conceito de desempenho ambiental, que nada mais é do que o consumo de materiais e de energia e o total de emissões por 1000 quilogramas de produto (unidade funcional). $O$ desempenho ambiental pode também escrito da seguinte forma:

Desempenho Ambiental embalagem $350 \mathrm{~g}=0,4$ (Ma); 1,2 (En); 0,2 (Em)

Desempenho Ambiental embalagem $650 \mathrm{~g}=0,3$ (Ma); 1,0 (En); 0,2 (Em) 
Leia-se, por exemplo, para a embalagem $350 \mathrm{~g}$ :

- $0,4 \mathrm{~kg}$ de materiais consumidos por $1000 \mathrm{~kg}$ de produto;

- $1,2 \mathrm{kWh}$ consumido por $1000 \mathrm{~kg}$ de produto;

- $0,2 \mathrm{~kg}$ de emissões por $1000 \mathrm{~kg}$ de produto.

Cabe aqui lembrar que este trabalho tem, como um de seus objetivos, colaborar na solução do "dilema da embalagem" em estudo. Para atender a este objetivo, foi proposta na Tabela 2 uma simulação para 1000 refeições com base nos dados da Tabela 1. Na situação denominada ideal, sem descarte de lasanha, em 1000 refeições, a embalagem 350 g consome mais material (39\%), mais energia (33\%) e gera menos (29\%) emissões que a de $650 \mathrm{~g}$,

Tabela 2 - Desempenho ambiental e o dilema da embalagem

\begin{tabular}{|c|c|c|c|c|c|c|}
\hline \multirow{2}{*}{ PARÂMETROS } & \multicolumn{2}{|c|}{ Materiais, kg } & \multicolumn{2}{|c|}{ Energia, kWh } & \multicolumn{2}{|c|}{ Emissões, kg } \\
\hline & Lasanha $350 \mathrm{~g}$ & Lasanha $650 \mathrm{~g}$ & Lasanha $350 \mathrm{~g}$ & Lasanha $650 \mathrm{~g}$ & Lasanha $350 \mathrm{~g}$ & Lasanha $650 \mathrm{~g}$ \\
\hline \multicolumn{7}{|c|}{ Desempenho ambiental por 1000 refeições - situação ideal } \\
\hline $\mathrm{kg} / 1000$ refeições & 125 & 95 & --- & --- & 78 & 62 \\
\hline kWh / 1000 refeições & $-\cdots$ & --- & 421 & 317 & --- & $-\cdots$ \\
\hline Diferença (embalagem $350 \mathrm{~g}$ - embalagem $650 \mathrm{~g}$ ) & \multicolumn{2}{|c|}{30} & \multicolumn{2}{|c|}{104} & \multicolumn{2}{|c|}{16} \\
\hline Diferença (embalagem $350 \mathrm{~g}$ - embalagem $650 \mathrm{~g}$ ), \% & \multicolumn{2}{|c|}{$32 \%$} & \multirow{2}{*}{\multicolumn{2}{|c|}{$33 \%$}} & \multicolumn{2}{|c|}{$26 \%$} \\
\hline \multicolumn{5}{|c|}{ Desempenho ambiental por 1000 refeições - com descarte de sobras } & & \\
\hline $\mathrm{kg} / 1000$ refeições & 125 & 190 & $-\cdots$ & $--\cdot$ & 78 & 324 \\
\hline kWh / 1000 refeições & $-\cdots$ & --- & 421 & 561 & --- & $--\cdot$ \\
\hline Diferença (embalagem $350 \mathrm{~g}$ - embalagem $650 \mathrm{~g}$ ) & \multicolumn{2}{|c|}{-65} & \multicolumn{2}{|c|}{-140} & \multicolumn{2}{|c|}{-246} \\
\hline Diferença (embalagem $350 \mathrm{~g}$ - embalagem $650 \mathrm{~g}$ ), \% & \multicolumn{2}{|c|}{$-34 \%$} & \multicolumn{2}{|c|}{$-25 \%$} & \multicolumn{2}{|c|}{$-76 \%$} \\
\hline
\end{tabular}

Fonte: Os autores.

Na situação denominada "com descarte de sobras", na qual $200 \mathrm{~g}$ de lasanha não são consumidas, em 1000 refeições, a embalagem 350 g consome menos material (34\%) e menos energia (25\%), e tem emissão menor (76\%) que a de $650 \mathrm{~g}$. Lembrando que a maior parte desta emissão é constituída de resíduos de alimentos. Eis o dilema da embalagem: se a embalagem $350 \mathrm{~g}$ for substituída totalmente pela de $650 \mathrm{~g}$ em nome do menor impacto ambiental calculado, a empresa correrá dois riscos; a) perda de vendas advinda do descontentamento dos consumidores single, e b) aumento no impacto ambiental pelo descarte de produto não consumido.

A questão que resume o "dilema da embalagem" de lasanha congelada pode então ser assim reescrita: Qual é a melhor alternativa: embalagens menores (350 g de produto), com quantidades adequadas para o público single, com risco de aumentar o impacto ambiental pelo maior consumo de material e de energia, ou embalagens maiores, com maior peso líquido ( $650 \mathrm{~g}$ de produto), com o risco de aumentar o desperdício de alimentos? Em outras palavras, atribuindo valores, qual a melhor alternativa, considerando como base 1000 refeições: aumentar o consumo e o descarte de embalagem em $125 \mathrm{~kg}$ e o consumo de energia em $317 \mathrm{kWh}$, ou aumentar em $190 \mathrm{~kg}$ o descarte do produto?

$\mathrm{Na}$ opinião dos autores, o dilema da embalagem para lasanha single se resolve adotando como premissas: 
- A embalagem $350 \mathrm{~g}$ (single) causa menor impacto ambiental que a de $650 \mathrm{~g}$ e, portanto, será a base para proposta de otimização na próxima etapa da metodologia;

- Todas as embalagens têm, impressas, claras instruções de quantidades a consumir de modo a transmitir a responsabilidade ambiental com a qual foi projetada. No caso específico da embalagem $650 \mathrm{~g}$ a orientação deve ser no sentido de adquirir para uma refeição de duas pessoas ou, se for single, após consumir, guarda no refrigerador para comer em outro momento;

- Todas as embalagens devem ser corretamente descartadas.

Com base no perfil ambiental foi possível identificar os pontos de maior impacto ambiental do sistema, e após analisá-los criteriosamente, selecionar as estratégias para alterar o sistema de embalagem atual ou projetar outro.

\subsection{Seleção das estratégias para o projeto}

Traçado o perfil ambiental dos produtos, foi elaborada a Lista de Estratégias focadas no sistema de embalagem que foi incluída na Matriz de Viabilidade da Tabela 3. Essa matriz utiliza como critérios de avaliação o prazo de execução e as viabilidades técnica e financeira. Na última coluna foram colocados os tipos de melhorias esperadas com cada ação. Estas ações operacionais foram submetidas ao Departamento de Desenvolvimento de Embalagem da empresa. Alguns dos itens não foram preenchidos porque requerem estudos adicionais. 
Tabela 3 - Estratégias e matriz de viabilidade para selecionar estratégias de Ecodesign

\begin{tabular}{|c|c|c|c|c|c|c|}
\hline ETAPAS & ESTRATÉGIAS & AÇÕES OPERACIONAIS & $p$ & VT & VF & MELHORA ESPERADA \\
\hline \multirow[t]{7}{*}{ Produção da embalagem } & $\begin{array}{l}\text { Seleção de materiais de baixo } \\
\text { impacto }\end{array}$ & Desenvolver bandeja sem PET & $\mathrm{L}$ & $S$ & 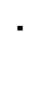 & $\begin{array}{l}\text { Eliminar material de fonte não-renovável } \\
\text { Aumentar reciclabilidade dos materiais }\end{array}$ \\
\hline & & Substituir verniz UV por outra alternativa. & $\mathrm{L}$ & $S$ & $S$ & Eliminar material do processo \\
\hline & & Utilizar papel cartão reciclado no cartucho & $\mathrm{L}$ & S & - & Otimizar a extração de matéria-prima \\
\hline & & Utilizar papel cartão reciclado na bandeja & $\mathrm{L}$ & N & - & Otimizar a extração de matéria-prima \\
\hline & Simplificação da embalagem & Desenvolver bandeja que não necessite do cartucho & L & $S$ & N & Reduzir consumo de material e energia e emissões \\
\hline & Redução do peso da embalagem & Reduzir gramatura do papel cartão das embalagens & C & S & $S$ & Reduzir consumo de papel cartão \\
\hline & Otimização impressão & Redimensionar tamanho das embalagens & C & S & $S$ & Reduzir material, energia e aparas de papel cartão \\
\hline \multirow[t]{3}{*}{ Logistica } & Otimização da paletização & Aumentar quantidade de produto por palete & C & $S$ & $S$ & Reduzir gasto de energia \\
\hline & Otimização distribuição & Reduzir distâncias entre fornecedores, tábrica e consumidores. & $\mathrm{L}$ & $S$ & N & Otimizar transporte e armazenamento \\
\hline & & Desenvolver embalagem que dispense refriceracão & $\mathrm{L}$ & S & N & $\begin{array}{l}\text { Reduzir energia e emissões de } \mathrm{CO} 2 \\
\text { Economizar energia da cadela do frio }\end{array}$ \\
\hline \multirow[t]{4}{*}{ Uso do produto } & Otimização do uso do produto & $\begin{array}{l}\text { Desenvolver embalagem que reduza o tempo de preparo no forno } \\
\text { microondas }\end{array}$ & $L$ & . & - & Economizar energia no preparo \\
\hline & & $\begin{array}{l}\text { Desenvolver embalagem que permita o consumo na própria, } \\
\text { dispensando o prato. }\end{array}$ & c & $S$ & $S$ & Economizar água da lavagem da louça \\
\hline & & & & & & Reduzir efluentes da lavagem da louça \\
\hline & & Incluir taheres descartáveis na embalagem & $\mathrm{L}$ & $S$ & S & $\begin{array}{l}\text { Aumentar conveniência do consumidor } \\
\text { Economizar áqua da lavagem da louca }\end{array}$ \\
\hline \multirow[t]{2}{*}{ Disposição final } & $\begin{array}{l}\text { Redução do impacto da embalagem } \\
\text { pós-consumo }\end{array}$ & $\begin{array}{l}\text { Acrescentar Informações de como dispor a embalagem } \\
\text { adequadamente }\end{array}$ & C & $S$ & $S$ & Estimular coleta seletiva \\
\hline & & Reduzir quantidade de embalagem pós-consumo & C & S & S & Reduzir descarte de materiais \\
\hline \multirow{2}{*}{\multicolumn{7}{|c|}{$\begin{array}{l}\text { LEGENDA: } \\
P=\text { Prazo }\end{array}$}} \\
\hline & & & & & & \\
\hline \multicolumn{7}{|l|}{$L=$ longo prazo } \\
\hline \multicolumn{7}{|l|}{$C=$ curto prazo } \\
\hline \multicolumn{7}{|l|}{ VT = viabilidade técnica } \\
\hline \multicolumn{7}{|l|}{$V F=$ viabilidade financeira } \\
\hline \multicolumn{7}{|l|}{$S=\operatorname{sim}$} \\
\hline & & & & & & \\
\hline
\end{tabular}

Fonte: Os autores.

Dentro do escopo deste trabalho, foram selecionadas as cinco ações operacionais em negrito na Tabela 3. As demais poderão vir a ser tema de projetos futuros da empresa.

\subsection{Especificação técnica do novo sistema de embalagem}

Foi proposta alternativa de embalagem para atender às cinco ações operacionais propostas no item anterior, que consiste em eliminar o cartucho e ajustar as propriedades e dimensões da bandeja da Figura 3 (b). As especificações técnicas do novo sistema de embalagem em comparação com a atual são apresentadas na Tabela 4. Ao eliminar o display houve uma economia equivalente a $69 \mathrm{~kg}$ de papel cartão e aproximadamente $2 \mathrm{~kg}$ de tinta e verniz por palete. A bandeja ficou menor e mais baixa, para facilitar o consumo na própria embalagem. Com isso, a embalagem primária além das funções de conter e proteger o produto, passa a agregar a identidade visual, as demais informações inicialmente impressas no display, inclusive a expressão "Material $100 \%$ reciclável" e 
uma recomendação de uso: "Consuma na própria embalagem". O verso pode ser utilizado como um canal de comunicação ambiental, estimulando o usuário a utilizar a coleta seletiva.

Tabela 4 - Especificações das embalagens $350 \mathrm{~g}$ - atual e proposta

\begin{tabular}{|c|c|c|}
\hline Especificações & Embalagem atual de $350 \mathrm{~g}$ & Embalagem nova de $350 \mathrm{~g}$ \\
\hline & Embalagem primária e display & \\
\hline \multicolumn{3}{|l|}{ Material } \\
\hline Cartucho (display) & Papel cartão Klakoad $278 \mathrm{~g} / \mathrm{m}^{2}$ & Não há \\
\hline Bandeja & Papel cartão com revestimento PET $373 \mathrm{~g} / \mathrm{m}^{2}$ & Papel cartão Suzano TP Polar \\
\hline Tampa & Papel cartão com revestimento PET $373 \mathrm{~g} / \mathrm{m}^{2}$ & Papel cartão Suzano TP Polar \\
\hline \multicolumn{3}{|l|}{ Impressão } \\
\hline Cartucho (display) & Off-set 6 cores + verniz UV & Não há \\
\hline Bandeja & Off-set 1 cor + verniz UV & Off-set 6 cores + verniz UV \\
\hline Tampa & Off-set 3 cores + verniz UV & Off-set 6 cores + verniz UV \\
\hline \multicolumn{3}{|l|}{$\begin{array}{l}\text { Dimensões } \\
\text { (montada), mm }\end{array}$} \\
\hline Comprimento & 125 & 141 \\
\hline Largura & 150 & 125 \\
\hline Altura & 35 & 25 \\
\hline Volume, mL & 450 & 450 \\
\hline \multicolumn{3}{|l|}{$\begin{array}{l}\text { Dimensões (aberta), } \\
\text { mm }\end{array}$} \\
\hline Comprimento & 194 & 201 \\
\hline \multirow[t]{2}{*}{ Largura } & 176 & 185 \\
\hline & Embalagem secundária & \\
\hline Material & Papelão ondulado onda C, $490 \mathrm{~g} / \mathrm{m}^{2}$ & Papelão ondulado onda C, $490 \mathrm{~g} / \mathrm{m}^{2}$ \\
\hline Impressão & Flexografia, 2 cores & Flexografia, 2 cores \\
\hline \multicolumn{3}{|l|}{ Dimensões, mm } \\
\hline Comprimento & 308 & 376 \\
\hline Largura & 206 & 282 \\
\hline Altura & 113 & 71 \\
\hline $\begin{array}{l}\text { Capacidade, } \\
\text { bandejas / caixa }\end{array}$ & 10 & 12 \\
\hline \multicolumn{3}{|l|}{ Paletização } \\
\hline \multicolumn{3}{|l|}{ Caixas (unidades) / } \\
\hline palete & 200 & 270 \\
\hline \multicolumn{3}{|l|}{ Bandejas (unidades) } \\
\hline / palete & 2000 & 3240 \\
\hline Produto $(\mathrm{kg}) /$ palete & 700 & 1134 \\
\hline
\end{tabular}

Fonte: Os autores.

Com alteração das dimensões da embalagem primária foi necessário redimensionar a embalagem secundária (caixa de embarque) e a embalagem de transporte (palete). A mesma Tabela 6 mostra as especificações das embalagens novas em comparação com a atual de $350 \mathrm{~g}$. $\mathrm{O}$ redimensionamento da bandeja, da caixa de embarque e da paletização permitiu um aumento, por palete, de $700 \mathrm{~kg}$ para $1134 \mathrm{~kg}$ de lasanha e de 2000 para 3240 unidades com $350 \mathrm{~g}$ de produto. Alterações na estrutura que ainda podem ser feitas em função dos testes de transporte a efetuar com os protótipos, não deverão alterar substancialmente a avaliação do desempenho ambiental das embalagens. 


\subsection{Avaliação do desempenho ambiental do novo sistema de embalagem}

A etapa final do projeto de Ecodesign consiste em avaliar os benefícios ambientais da "nova embalagem", comparando-os com o atual das lasanhas de $350 \mathrm{~g}$ e 650 g. A comparação teórica baseou-se nas informações do levantamento de inventário das embalagens atuais. Foi definida a mesma unidade funcional de $1000 \mathrm{~kg}$ de lasanha e, posteriormente, recalculadas as tabelas de inventário para as novas especificações.

Na Tabela 5 é apresentada a simulação do inventário da nova embalagem comparado com as atuais. Observa-se, pela sua análise, que a embalagem de $350 \mathrm{~g}$ atual consome $0,4 \mathrm{~kg}$ de embalagem para $1 \mathrm{~kg}$ de produto, enquanto a nova embalagem, também de $350 \mathrm{~g}$, consome 0,2 $\mathrm{kg}$ de embalagem / kg de lasanha, fato que ilustra a melhoria no desempenho ambiental. No tocante ao consumo de energia por produto, a relação kWh por kg de produto cai de 1,3 para 1,1. Por fim, as emissões são reduzidas de 5,9 kg de emissões por quilo de produto, para 3,0 kg de emissões por quilo de lasanha. $O$ desempenho ambiental da nova embalagem pode ser escrito como se segue:

$$
\text { Desempenho Ambiental = 0,2 (Ma); 1,1 (En); 0,1 (Em) }
$$

Tabela 5 - Inventário de materiais, energia e emissões das embalagens atuais $350 \mathrm{~g}$ e $650 \mathrm{~g}$ e nova $350 \mathrm{~g}$, por $1000 \mathrm{~kg}$ de produto

\begin{tabular}{|c|c|c|c|c|c|c|c|c|c|}
\hline \multirow{2}{*}{ Etapas do processo } & \multicolumn{3}{|c|}{ Materiais, $\mathrm{kg}$} & \multicolumn{3}{|c|}{ Energia, kWh } & \multicolumn{3}{|c|}{ Emissões, kg } \\
\hline & Lasanha $350 \mathrm{~g}$ & Lasanha $650 \mathrm{~g}$ & Nova $350 \mathrm{~g}$ & Lasanha $350 \mathrm{~g}$ & Lasanha $650 \mathrm{~g}$ & Nova $350 \mathrm{~g}$ & Lasanha $350 \mathrm{~g}$ & Lasanha $650 \mathrm{~g}$ & Nova $350 \mathrm{~g}$ \\
\hline \multicolumn{10}{|l|}{ Produção embalagem } \\
\hline$\overline{\text { Total produção embalagem }}$ & 171 & 145 & 70 & 62 & 44 & 21 & 47 & 51 & 4 \\
\hline Total produção embalagem por kg produto (*) & 0,2 & 0,1 & 0,1 & 0,1 & $<0,1$ & 0,0 & $<0,1$ & $<0,1$ & $<0,1$ \\
\hline \multicolumn{10}{|l|}{ Linha de envase } \\
\hline$\overline{\text { Total linha de envase }}$ & 125 & 94 & 66 & 235 & 235 & 235 & 0 & 0 & 0,0 \\
\hline Total linha de envase por kg produto (*) & 0,1 & 0,1 & 0,1 & 0,3 & 0,2 & 0,4 & 0,0 & 0,0 & 0,0 \\
\hline \multicolumn{10}{|l|}{ Logística } \\
\hline Total logistica & 60 & 54 & 61 & 205 & 183 & 178 & 51 & 46 & 54 \\
\hline Total logística por kg de produto (*) & 0,1 & 0,1 & 0,1 & 0,2 & 0,2 & 0,3 & 0,1 & $<0,1$ & $<0,1$ \\
\hline \multicolumn{10}{|l|}{ Uso do produto } \\
\hline Total uso do produto - situação ideal & 0 & 0 & 0 & 702 & 514 & 683 & 0 & 0 & 0 \\
\hline Total uso do produto por kg produto - situação ideal (*) & 0,0 & 0,0 & 0,0 & 0,7 & 0,6 & 1,0 & 5,7 & 6,2 & 2,9 \\
\hline \multicolumn{10}{|l|}{ Disposição final } \\
\hline Total disposição final - situação ideal & 0 & 0 & 0 & 0 & 0 & 0 & 125 & 94 & 66 \\
\hline TOTAL · SITUAÇÃO IDEAL & 356 & 293 & 197 & 1204 & 976 & 1117 & 223 & 191 & 124 \\
\hline TOTAL POR kg PRODUTO - SITUAÇÃO IDEAL (*) & 0,4 & 0,3 & 0,2 & 1,2 & 1,0 & 1,1 & 0,2 & 0,2 & 0,1 \\
\hline
\end{tabular}

Fonte: Os autores.

Comparando o desempenho de todas as embalagens para lasanha congelada de $350 \mathrm{~g}$ e 650 $\mathrm{g}$ atuais e $350 \mathrm{~g}$ da proposta nova (Tabela 6), concluiu-se que o novo sistema de embalagem apresenta melhorias nos aspectos ambientais, segundo os critérios utilizados, uma vez que consome menos materiais, energia e gera menos emissões. 
Tabela 6 - Comparação entre o desempenho ambiental das embalagens

\begin{tabular}{llll}
\hline Embalagem & Material (kg) & Energia (kWh) & Emissões (kg) \\
\hline Lasanha 350 g - atual & 0,3 & 1,2 & 0,2 \\
Lasanha 650 g - atual & 0,3 & 0,8 & 0,2 \\
Lasanha 350 g - proposta & 0,2 & 1,1 & 0,1 \\
Variação 350 g proposta - atual & $-0,1$ & $-0,1$ & $-0,1$ \\
\hline
\end{tabular}

Fonte: Os autores.

Em suma, foi constatado nesta simulação que a embalagem nova cumpriu seus objetivos, contendo a mesma quantidade de produto com menos impacto ambiental, inclusive comparada com a embalagem de $650 \mathrm{~g}$. Os fatores que mais contribuíram para isso foram: eliminação da embalagem display; otimização da embalagem secundária que passou a conter 12 unidades de lasanha ao invés de 10 . Outros benefícios da embalagem proposta também podem ser enumerados:

- Otimização do transporte: com a nova embalagem, 1 palete carrega 3240 bandejas podendo transportar mais produtos por viagem;

- Otimização de materiais: substituindo o papel cartão laminado com PET na bandeja e tampa pelo papel Suzano TP Polar sem PET e 100\% reciclável, otimizou-se o processo de revalorização da embalagem depois da disposição final que pode ser totalmente reciclada, ou caso acabe no aterro sanitário, degrada-se mais rapidamente. Além disso, evita-se a utilização de material de origem fóssil e não renovável como o PET. Houve também a redução dos materiais com a eliminação do cartucho;

- Otimização no uso - trouxe mais conveniência para o consumidor oferecendo uma embalagem em formato mais anatômico e permitindo que o produto seja consumido na própria embalagem, reduzindo o consumo de água na lavagem da louça;

- Otimização na disposição final - eliminando o cartucho reduziu-se a quantidade de lixo. A embalagem passou a informar ao consumidor como descartá-la corretamente, contribuindo para a educação ambiental.

O desempenho mecânico da nova embalagem, e os eventuais ajustes das especificações, sem que haja previsão de comprometimento dos resultados deste trabalho, ainda deverá ser objeto de estudos complementares.

\section{Avaliação dos resultados}

Por meio deste estudo foi possível utilizar a metodologia do Ecodesign para o Sistema de Embalagem da lasanha congelada, ajustando o projeto atual em determinadas etapas do ciclo de vida e propondo estratégias para o desenvolvimento de uma embalagem alternativa. Os aspectos positivos e negativos da metodologia são abordados a seguir.

\section{Aspectos positivos da metodologia}

Sintetiza ferramentas e conceitos sobre como proceder para minimizar o impacto ambiental de um produto em todas as etapas do ciclo de vida. Muitas estratégias como por exemplo: redução na fonte, utilização de materiais recicláveis ou de origem renovável, são conhecidas e adotadas isoladamente por algumas empresas, entretanto, a metodologia do Ecodesign demonstra como selecionar e combinar as estratégias tirando o máximo proveito de cada uma delas;

- Dissemina uma visão sistêmica sobre os aspectos ambientais da embalagem ampliando as possibilidades para minimizar o impacto ambiental, não se restringindo a chavões como o 
de que basta reciclar a embalagem no final da vida útil que o problema está resolvido. Os profissionais envolvidos com o Ecodesign passam automaticamente a pensar no projeto de embalagem considerando seu ciclo de vida;

- Muitas empresas estão familiarizadas com a norma ISO 14001 sobre gestão ambiental e com técnicas de produção mais limpa, mas ainda não projetam sistemas de embalagem com responsabilidade ambiental. Algumas empresas depois do projeto acabado, apenas procuram colocar um detalhe na embalagem para dizer que é ecologicamente correta. A adoção do Ecodesign como ferramenta de projeto pode realmente fazer diferença;

- Aproxima os diversos setores da empresa na medida em que requer uma equipe multidisciplinar e, com isso, pode difundir a cultura da responsabilidade ambiental em todos;

- É um instrumento que leva à inovação, uma vez que estimula a equipe de projeto a repensar as funções da embalagem e buscar alternativas;

- Não requer grandes investimentos além de tempo dos profissionais para levantar o perfil ambiental das embalagens.

\section{Aspectos negativos}

- Por trabalhar com dados qualitativos pode estar sujeita a influência da interpretação da equipe e por isso apresentar desvios que podem comprometer a credibilidade dos resultados. Pode não oferecer fundamento para uma possível certificação ambiental, como ocorre com os estudos de ciclo de vida;

- A maioria das estratégias sugeridas na literatura não é aplicada diretamente em sistemas de embalagens. Por este motivo, são necessários mais estudos semelhantes a este, até que a metodologia esteja otimizada.

\section{Conclusões}

O trabalho atingiu aos objetivos propostos, a partir do momento em que, avaliou a metodologia do Ecodesign através da sua aplicação no sistema de embalagem da lasanha congelada destinada ao público single, permitindo, desta forma, analisar os impactos ambientais por ele causados, além de apresentar propostas e estratégias para minimizá-los.

Ao comparar a embalagem de lasanha congelada de $350 \mathrm{~g}$, ela apresenta menor impacto ambiental do que a embalagem de $650 \mathrm{~g}$, uma vez que o público single, ao consumir o produto desta última, fatalmente levará ao descarte de alimento. Outro aspecto importante, é que a embalagem alternativa proposta pelo trabalho, apresenta um desempenho ambiental ainda menor do que a de $350 \mathrm{~g}$ atual, este fato resolve o "dilema da embalagem" para o produto em questão.

Avaliando os resultados da pesquisa, verifica-se que o Ecodesign contribui para as empresas projetarem embalagem com responsabilidade ambiental. A metodologia pode e deve ser aprimorada pelas equipes de projeto, adaptando-a às próprias necessidades e agregando outras ferramentas, da mesma forma que sofreu alterações para ser utilizada no sistema de embalagem da lasanha. Enfim, ao lado do mecanismo de gestão ambiental, produção mais limpa e avaliação de ciclo de vida, o Ecodesign pode ser uma importante ferramenta para aumentar o desempenho ambiental dos produtos, contribuindo para o desenvolvimento sustentável das empresas. Por fim, os autores esperam ter colaborado para aumentar a massa crítica sobre Ecodesign aplicado no setor de alimentos e que este trabalho possa ser enriquecido por outras pesquisas. 


\section{REFERÊNCIAS BIBLIOGRÁFICAS}

ASSOCIAÇÃO BRASILEIRA DE NORMAS TÉCNICAS. NBR ISO 14040: Gestão ambiental - avaliação do ciclo de vida - princípios e estrutura. São Paulo, 2001.

ASSOCIAÇÃO BRASILEIRA DE NORMAS TÉCNICAS. NBR ISO/TR 14062: Gestão ambiental Integração de aspectos ambientais no projeto e desenvolvimento do produto. São Paulo, 2004.

BOBST Speria. USA: Bobst, 2006. 20p. Disponível em: <http://www.bobstgroup.com/ UploadSite/05/Download_page.asp> Acesso em: 21 out. 2006.

BOSCH automotive handbook. 5. ed. USA: Bentley Publishers, 2000. 900 p.

BRASIL. Instituto Brasileiro de Meio Ambiente (IBAMA). Programa de Controle da Poluição do Ar por Veículos Automotores (Proconve). Brasília, DF. Disponível em: <www.ibama.gov.br/proconve/login.php>. Acesso em: 26 ago. 2006.

BREZET, V.; HEMEL C. Ecodesign: a promising approach to sustainable production and consuption. Paris: United Nations Publication, 1997. 346p.

CABRAL, A.C.D. Manual básico para desenvolvimento de embalagens laminadas flexíveis. São Paulo: Abraflex, 2003. 39p.

CABRAL, A.C.D. Qualidade total em sistemas de embalagem para alimentos. In: CONGRESSO BRASILEIRO DE CIÊNCIA E TECNOLOGIA DE ALIMENTOS, 14, 1994, Campinas. Anais... Campinas: SBCTA, 1994. p.26-40.

CERTEL - COOPERATIVA REGIONAL DE ELETRIFICAÇÃO TEUTONIA (CERTEL). O consumo de energia elétrica, 2006. Disponível em: <http://www.certelnet.com.br/consumo.php>. Acesso em: 17 out. 2006.

CETEA/CEMPRE. Avaliação do ciclo de vida, princípios e aplicações. Campinas: Cetea/Cempre, 2002. 92p.

FIKSEL, J. Design for environment: creating eco-efficient products and processes. EUA: Ed. McGrawHill, 1995. 514p.

LEWIS, H.; GERTSAKIS J.; et al. Design + environment: a global guide to designing greener goods. Reino Unido: Greenleaf Publishing Limited, 2001. 200p.

MADI, L.; COSTA, ACPB; REGO, R. A. Brasil food trends 2020. São Paulo: FIESP: ITAL, 2010.

MANZINI, Ezio; VEZZOLI, Carlo. O desenvolvimento de produtos sustentáveis. Os requisitos ambientais dos produtos industriais. Edusp, 2002.

NATIONAL RESEARCH COUNCIL (Canadá). Design for environment guide. Canadá. Disponível em: <http://www.dfe-sce.nrc-cnrc.gc.ca/home_e.html>. Acesso em: 4 ago. 2004.

SARANTÓPOULOS, C.I.G.L.; OLIVEIRA, L.M.; CANAVESI, E. Requisitos de Conservação de Alimentos em Embalagens Flexíveis. Campinas: CETEA/ITAL, 2001. 215 p.

TUDELFT - ECODISEÑO EN CENTROAMÉRICA MANUAL. Disponível em: <http://www.io.tudelft.nl/ research/dfs/ecodiseno/manual.htm> Acesso em: 29 jan. 2005.

YIN, R. K. Case study resarch: design and methods. Newbury Park: Sage, 1989. 166p. 